\title{
Compact Circularly Polarized Patch Antenna for WiMAX Applications with Improved Impedance Bandwidth and Axial Ratio
}

\author{
Ravikanti Swetha \\ Electronics and Communication Engineering \\ National Institute of Technology \\ Warangal, India \\ swetha.rks@nitw.ac.in
}

\author{
L. Anjaneyulu \\ Electronics and Communication Engineering \\ National Institute of Technology \\ Warangal, India \\ anjan@nitw.ac.in
}

\begin{abstract}
This paper presents a circularly polarized microstrip patch antenna for WiMAX (Worldwide Interoperability for Microwave Access) application with improved impedance bandwidth and axial ratio compared to the existing designs. The antenna is designed at a resonant frequency of $3.56 \mathrm{GHz}$ on the FR4 substrate with $2 \mathrm{~mm}$ thickness. The dimensions of the antenna are $0.35 \lambda_{0} \times 0.35 \lambda_{0} \times 0.023 \lambda_{0}$ and it is fed through a probe feed. An impedance bandwidth of $360 \mathrm{MHz}(10.11 \%)$ in the frequency range of $3.44 \mathrm{GHz}-3.8 \mathrm{GHz}$, with a gain of $3.16 \mathrm{dBi}$, axial ratio bandwidth of $1.9 \%(3.56 \mathrm{GHz}-3.63 \mathrm{GHz})$ and $\mathrm{VSWR}<2$ are obtained.
\end{abstract}

Keywords-microstrip patch antenna; circular polarization; probe feed; WiMAX applications

\section{INTRODUCTION}

Microstrip patch antennas are in great demand because of advantages such as their low profile, they are compact in size, the conformity to the supporting structure, and their flexibility and ease of fabrication. One of the important applications of this antenna is the use of transmitting or receiving systems that require circular polarization. Circular polarization is obtained by perturbing an unsymmetrical structure which results in orthogonal field components with quadrature phase-shift [1-3]. Circularly polarized antennas are more useful in wireless communications, RFID (radio-frequency identification), wireless LAN, and GPS. As of today these are the most opted due to the flexibility in the antenna positioning, the fewer misalignment losses, and the less interference between signals [4-5]. Circular polarization is classified by the number of feed points on the microstrip antenna. A single feed is more advantageous since it does not require an external polarizer [6]. Various techniques can be applied to the patch to create perturbation which in turn results in circular polarisation such as a capacitor loaded on an annular ring slotted patch [7], loading of shorting pins [8], capacitive and inductive loading techniques [9], and loading shorting elements in the patch [10]. Slits and slots formation on the patch [11-14], truncated corners [15], and capacitor loading produce very less impedance bandwidth and narrow axial ratio. The loading of shorting pins gives larger gain but little in bandwidth and is not compact. A new low cost structure is proposed in order to improve the impedance bandwidth and axial ratio when compared to the above techniques. For WiMAX application, according to the IEEE 802.16 standard, the frequency bands are $3.3 \mathrm{GHz}-$ $3.4 \mathrm{GHz}, 3.4 \mathrm{GHz}-3.6 \mathrm{GHz}$, and $3.6 \mathrm{GHz}-3.8 \mathrm{GHz}$ in various regions.

\section{DESIGN OF THE PROPOSED STRUCTURE}

The proposed Circularly Polarized Patch Antenna (CPPA) of circular shape with radius $\mathrm{r}=10.4 \mathrm{~mm}$ is designed using FR4 substrate of thickness $\mathrm{h}=2 \mathrm{~mm}$ and $\varepsilon_{\mathrm{r}}=4.4$. The dimensions of the patch antenna with the ground plane on the other side are shown in Figure 1. Triangular shaped narrow slits are cut on the four quadrants of the circular patch.

(a)
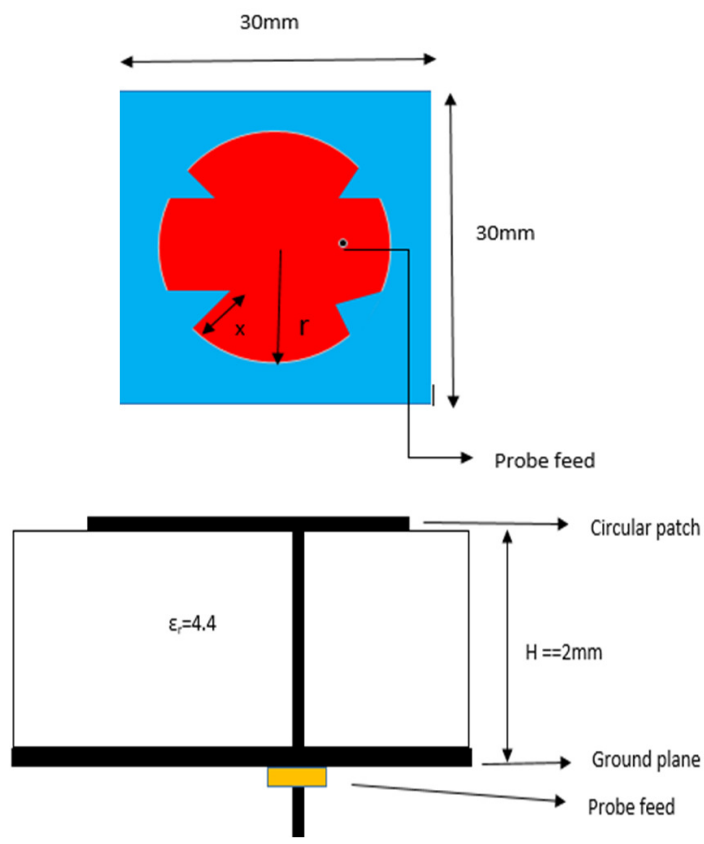

Fig. 1. Layout of the proposed antenna: (a) top view, (b) cross-sectional view 
One of the corner slits is cut deeper to create asymmetry in the structure which in turn results in circular polarization. Here $\mathrm{x}$ is the distance between the corner edge ends to the slit edge. The patch is fed through the probe feed at an optimal position.

\section{SimULATION RESULTS}

\section{A. Parametric Analysis}

The performance of the proposed antenna structure is investigated using the IE3D 12.0 CAD tool which is based on the method of moments. As illustrated in Figure 2, the axial ratio for various values of $\mathrm{x}$ is simulated. As the value of $\mathrm{x}$ decreases, the axial ratio decreases. The return loss for various feed point locations is also simulated (Figure 3 ). The optimum feed point location is chosen to be $(5,0)$. The optimum value of $\mathrm{x}$ is chosen to be $6.58 \mathrm{~mm}$ because if it is reduced below this value, the axial ratio bandwidth decreases again. The surface current distributions at the resonant frequency are shown in Figure 4.

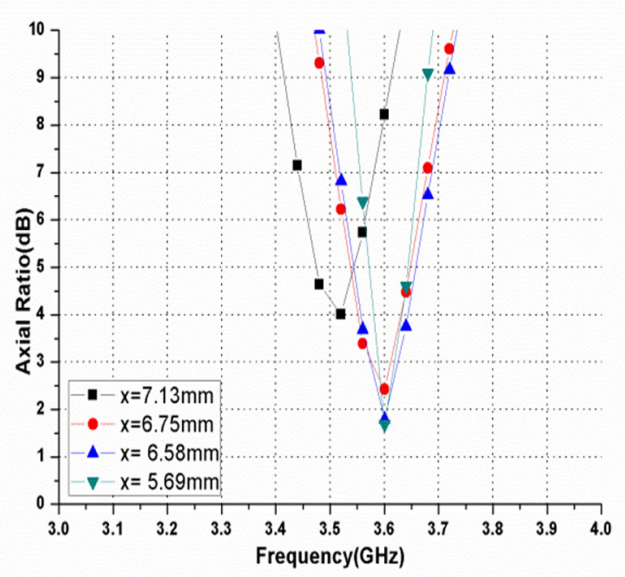

Fig. 2. Simulated axial ratio for the proposed antenna for different values of $x$

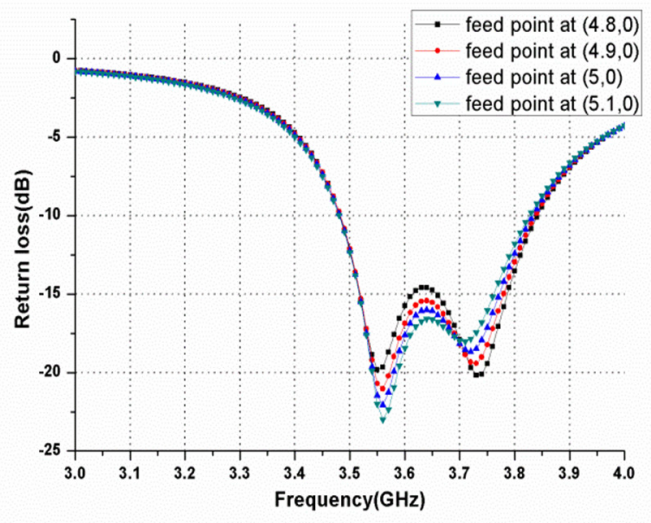

Fig. 3. Simulated return loss for the proposed antenna for different feed point locations

\section{B. Smith Chart}

Smith chart gives the impedance of the antenna at the resonant frequency. Figure 5 shows that the impedance of the antenna is $50 \Omega$. It clearly shows that impedance matching occurs at the resonant frequency, so the proposed antenna is suitable for the WIMAX application.

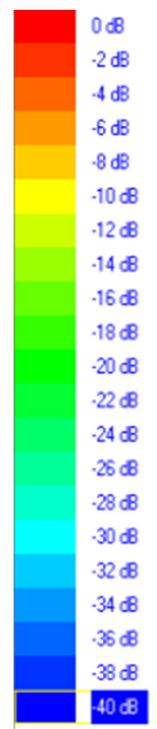

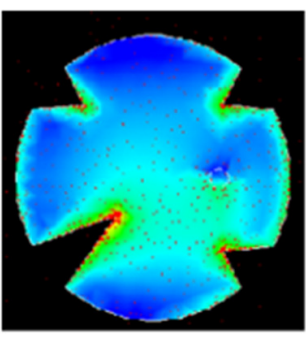

$t=0$

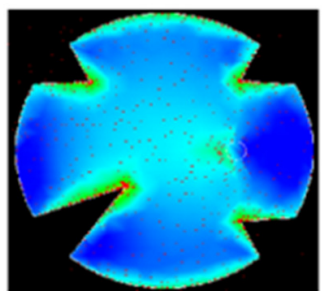

$t=\mathrm{T} / 2$

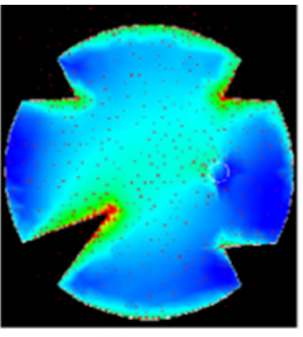

$t=\mathrm{T} / 4$

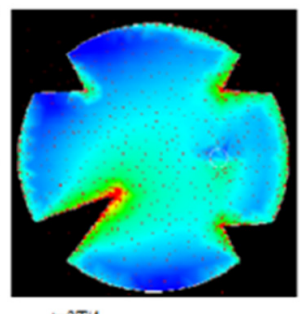

$\Leftrightarrow=3 \mathrm{I}^{4}$
Fig. 4. Simulated current distributions of the proposed antenna at the resonant frequency of $3.56 \mathrm{GHz}$

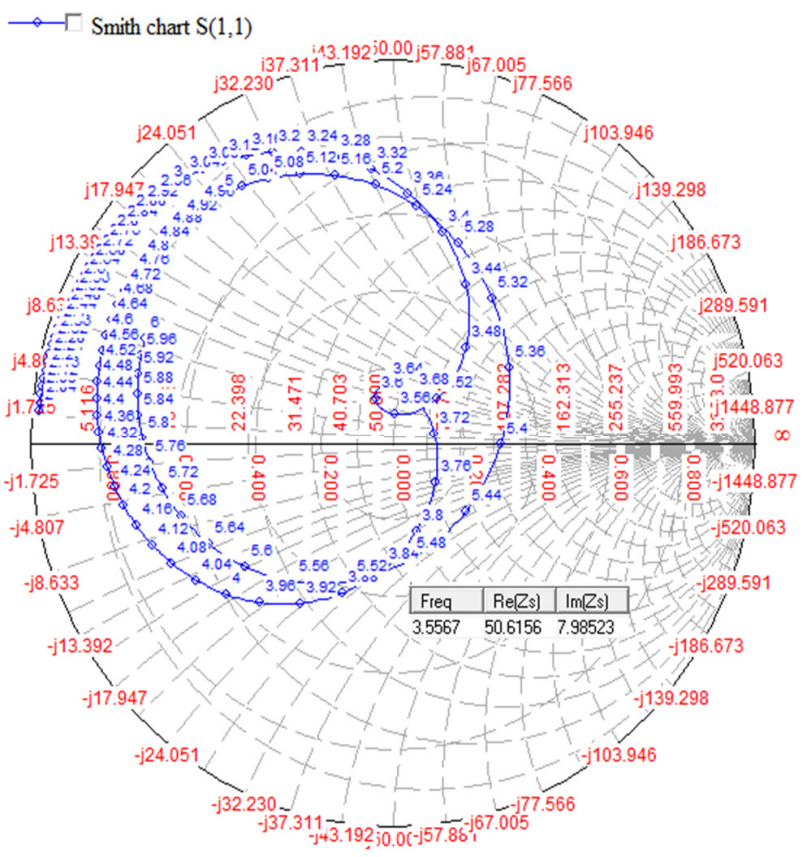

Fig. 5. Smith chart of the antenna.

IV. MEASURED RESULTS

The antenna, fabricated on low cost FR4 substrate, is shown in Figure 6. 


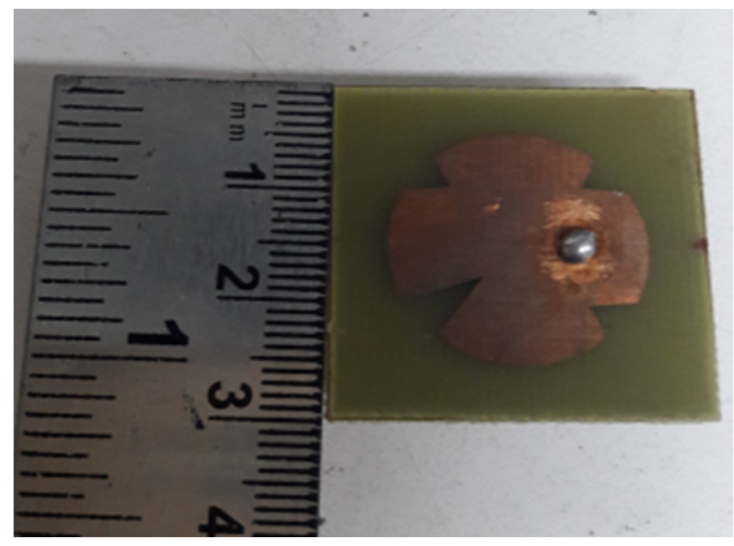

Fig. 6. Fabricated antenna designed at $3.56 \mathrm{GHz}$

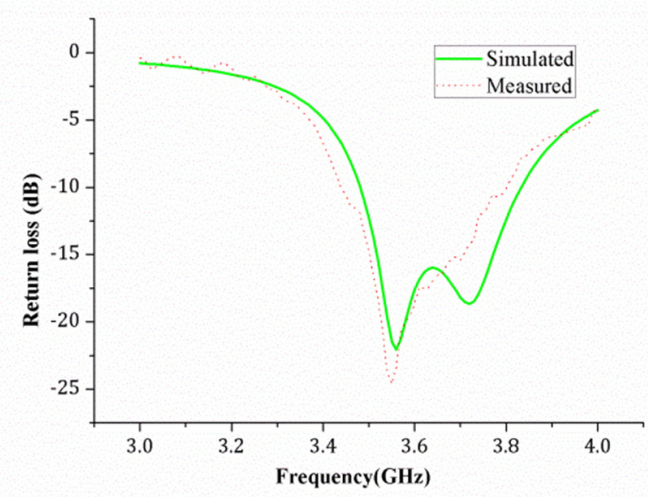

Fig. 7. Simulated and measured results for return loss at resonant frequency

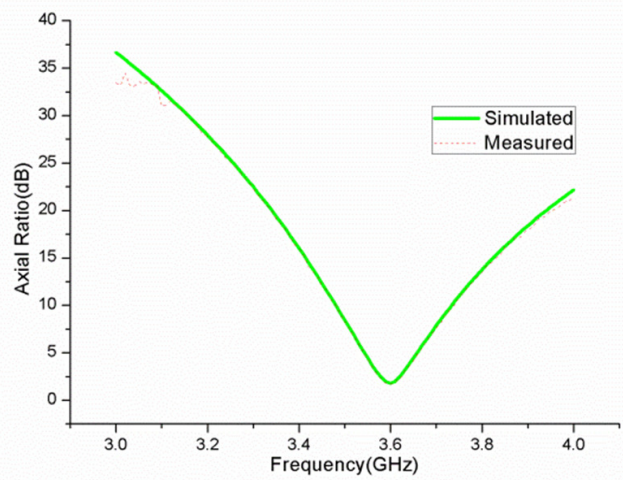

Fig. 8. Simulated and measured results for axial ratio at resonant frequency

\section{A. Return Loss}

To check the performance of the proposed design the return loss is shown in Figure 7. For the fabricated antenna, the measured return loss is $-26.5 \mathrm{~dB}$ at the resonant frequency of $3.56 \mathrm{GHz}$ with $10 \mathrm{~dB}$ impedance bandwidth of $360 \mathrm{MHz}$ falling in the range of $3.44 \mathrm{GHz}-3.8 \mathrm{GHz}$. This clearly shows that the designed antenna is suitable for WiMAX applications.

\section{B. Axial Ratio}

The axial ratio is a parameter that indicates the circular polarization of an antenna and is shown in Figure 8. For the proposed antenna, an axial ratio of $1.7 \mathrm{~dB}$ and a bandwidth of $70 \mathrm{MHz}$ in the frequency range of $3.56 \mathrm{GHz}-3.63 \mathrm{GHz}$ are obtained. The gain graph is shown in Figure 9. The performance parameters are summarized in Table I. The radiation patterns in azimuth and elevation planes and VSWR (voltage standing wave ratio) are shown in Figures 10-12.

\section{TABLE I. PARAMETERS OF THE PROPOSED ANTENNA}

\begin{tabular}{|c|c|c|c|c|}
\hline $\begin{array}{c}\text { Resonant } \\
\text { frequency } \\
\text { (GHz) }\end{array}$ & $\begin{array}{c}\text { Return loss } \\
\text { bandwidth } \\
\text { (MHz, \%) }\end{array}$ & $\begin{array}{c}\text { Gain } \\
\text { (dBi) }\end{array}$ & $\begin{array}{c}\text { Axial ratio } \\
\text { bandwidth } \\
\text { (MHZ, \%) }\end{array}$ & $\begin{array}{c}\text { Axial ratio } \\
\text { (dB) }\end{array}$ \\
\hline 3.56 & $360,10.11$ & 3.2 & $70.1,9 \%$ & 1.7 \\
\hline
\end{tabular}

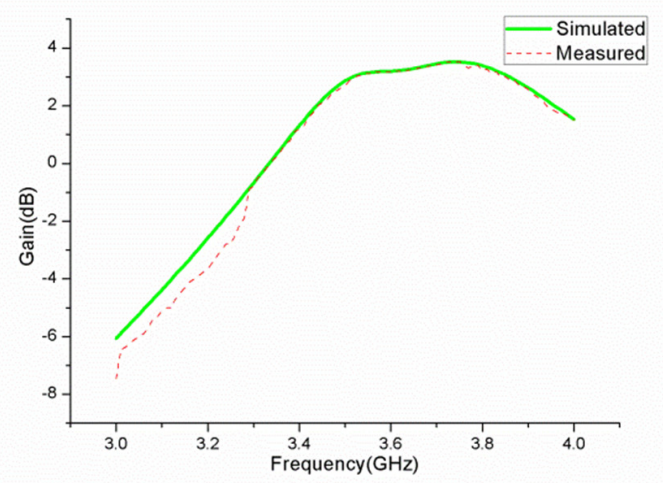

Fig. 9. Simulated and measured results for gain at resonant frequency

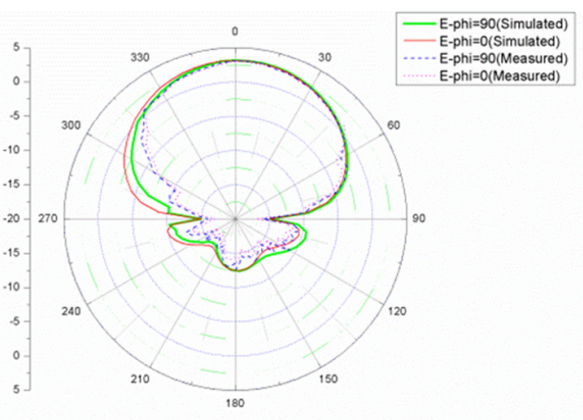

Fig. 10. 2D elevation radiation patterns at $3.56 \mathrm{GHz}$

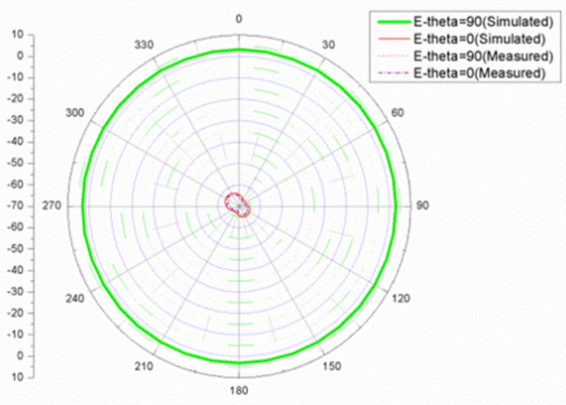

Fig. 11. 2D azimuth radiation patterns at $3.56 \mathrm{GHz}$ 


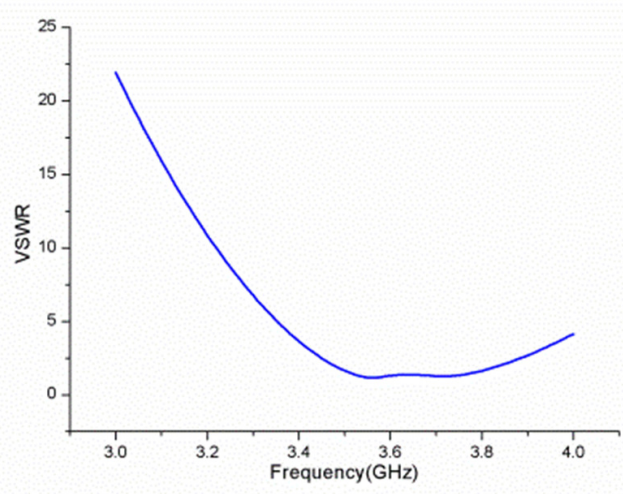

Fig. 12. VSWR of the proposed antenna

TABLE II. COMPARISON BETWEEN EXISTING TECHNIQUES

\begin{tabular}{|c|c|c|c|}
\hline Reference & $\begin{array}{c}\text { Return loss impedance } \\
\text { bandwidth (MHz) }\end{array}$ & $\begin{array}{c}\text { Axial ratio } \\
\text { bandwidth (MHz) }\end{array}$ & $\begin{array}{c}\text { Gain } \\
\text { (dBi) }\end{array}$ \\
\hline$[7]$ & 62 & 18 & 5 \\
\hline$[8]$ & 150 & 30 & 10.6 \\
\hline$[9]$ & 250 & - & 4.43 \\
\hline$[10]$ & 80 & 21 & 3.8 \\
\hline$[12]$ & 50 & 12 & 4.3 \\
\hline Proposed & 360 & 70 & 3.16 \\
\hline
\end{tabular}

\section{Discussion}

The performance of the proposed antenna is better than the one of the existing designs. The inductive and capacitive loading technique to generate circular polarization yielded low return loss and compact size. The loading of shorting pins creates short from the ground to the patch producing a low impedance bandwidth. The formation of slits and slots on the patch varies the results a lot, which depend on the shape, size and position on the patch. A comparison of these techniques in terms of return loss, axial ratio and gain with the proposed design is made and listed in Table II. The proposed antenna's measured and simulated results show good agreement.

\section{CONCLUSION}

In this paper, a circularly polarized patch antenna is fabricated at $3.56 \mathrm{GHz}$ for WiMAX application. The proposed antenna's dimensions are $0.35 \lambda_{0} \times 0.35 \lambda_{0} \times 0.023 \lambda_{0}$. Return loss of $360 \mathrm{MHz}$, axial ratio bandwidth of $70 \mathrm{MHz}$ and a gain of $3.16 \mathrm{dBi}$ were obtained. Parametric analysis was done for various feed point locations, to obtain better return loss characteristics, and for different values of depth of one of the slits, to obtain a better axial ratio. Measured and simulated results show good agreement. The proposed antenna is of low cost, compact and better than the existing designs.

\section{ACKNOWLEDGMENT}

The authors would like to thank the Department of ECE, NIT Warangal for providing the requisite software.

\section{REFERENCES}

[1] S. Ravikanti, L. Anjaneyulu, "A survey on miniaturization of circularly polarized antennas for future wireless communications", in: Electronics and communications engineering: applications and innovations, CRC Press, 2019

[2] K. R. Carver, J. W. Mink, "Microstrip antenna technology", IEEE Transactions on Antennas and Propagation, Vol. AP 29, No. 1, pp. 1-24, 1981

[3] J. R. James, P. S. Hall, Handbook of microstrip antennas, Peregrinus, 1989

[4] A. Bousselmi, A. Gharsallah, T. P. Vuong, "A novel high-gain quadband antenna with AMC metasurface for satellite positioning systems", Engineering, Technology \& Applied Science Research Vol. 9, No. 5, pp. 4581-458, 2019

[5] M. M. Teymoori, J. M. Ahangarkolaei, "A tunable capacitor based on MEMS technology for RF applications", Engineering, Technology \& Applied Science Research Vol. 6, No. 3, pp. 982-986, 2016

[6] P. C. Sharma, K. C. Gupta, "Analysis and optimized design of single feed circularly polarized microstrip antennas", IEEE Transactions on Antennas and Propagation, Vol. Ap-31, No. 6, pp. 949-955 1983

[7] J. Li, B. He, L. Li, A. Zhang, J. Liu, Q. H. Liu, "Capacitor-loaded circularly polarized annular-ring slotted microstrip patch antenna", 11 th International Symposium on Antennas, Propagation and EM Theory, Guilin, China, October 18-21, 2016

[8] X. Zhang, L. Zhu, "High-gain circularly polarized microstrip patch antenna with loading of shorting pins", IEEE Transactions on Antennas and Propagation, Vol. 64, No. 6, pp. 2172-2178, 2016

[9] D. Wang, H. Wong, C. H. Chan, "Small circularly polarized patch antenna", International Workshop on Antenna Technology, Hong Kong, China, March 7-9, 2011

[10] H. Wong, K. Kanso, K. Bo Ng, K.i M. Luk, C. H. Chan, Q. Xue, "Virtually shorted patch antenna for circular polarization", IEEE Antennas and Wireless Propagation Letters, Vol. 9, pp. 1213-1216, 2010

[11] Nasimuddin, X. Qing, Z. N. Chen, "A compact circularly polarized slotted patch antenna for GNSS applications", IEEE Transactions on Antennas and Propagation, Vol. 62, No. 12, pp. 6506-6509, 2014

[12] Nasimuddin, X. Qing, Z. N. Chen, "Compact asymmetric-slit microstrip antennas for circular polarization", IEEE Transactions on Antennas and Propagation, Vol. 59, No. 1, pp. 285-288, 2011

[13] W. S. Chen, C. K. Wu, K. L. Wong, "Novel compact circularly polarized square microstrip antenna", IEEE Transactions on Antennas and Propagation, Vol. 49, No. 3, pp. 3340-342, 2001

[14] H. Iwasaki, "A circularly polarized small-size microstrip antenna with a cross slot", IEEE Transactions on Antennas and Propagation, Vol. 44, No. 10, pp. 1399-1401, 1996

[15] W. S. Chen, C. K. Wu, K. L. Wong, "Single-feed square-ring microstrip antenna with truncated cornersfor compact circular polarisation operation", Electronics Letters, Vol. 34, No. 11, pp. 1045-1047, 1998

[16] IE3D Manual Version, Release 12, Zealand Software, Inc., 2006 